\title{
BMJ Open Economic evaluation of a novel community-based diabetes care model in rural Mexico: a cost and cost- effectiveness study
}

\author{
Kevin I Duan (D) , ${ }^{1}$ Francisco Rodriguez Garza, ${ }^{2}$ Hugo Flores, ${ }^{3,4}$ \\ Daniel Palazuelos, ${ }^{3,4,5,6}$ Jimena Maza, ${ }^{4}$ Luis Alberto Martinez-Juarez (D) , ${ }^{7}$ \\ Patrick F Elliott, ${ }^{8}$ Elena Moreno Lázaro, ${ }^{9}$ Natán Enriquez Rios, ${ }^{9}$ Gustavo Nigenda, ${ }^{10}$ \\ Lindsay Palazuelos, ${ }^{4,6}$ Ryan K McBain ${ }^{6,11}$
}

To cite: Duan Kl, Rodriguez Garza F, Flores $\mathrm{H}$, et al. Economic evaluation of a novel community-based diabetes care model in rural Mexico: a cost and costeffectiveness study. BMJ Open 2021;11:e046826. doi:10.1136/ bmjopen-2020-046826

- Prepublication history and additional supplemental materials for this paper is available online. To view these files, please visit the journal online (http://dx.doi.org/10. 1136/bmjopen-2020-046826)

Received 11 November 2020 Revised 23 February 2021 Accepted 18 March 2021

Check for updates

(C) Author(s) (or their employer(s)) 2021. Re-use permitted under CC BY-NC. No commercial re-use. See rights and permissions. Published by BMJ.

For numbered affiliations see end of article.

Correspondence to

Dr Kevin I Duan; kduan@uw.edu

\section{ABSTRACT}

Objectives Diabetes is the leading cause of disabilityadjusted life years in Mexico, and cost-effective care models are needed to address the epidemic. We sought to evaluate the cost and cost-effectiveness of a novel community-based model of diabetes care in rural Mexico, compared with usual care.

Design We performed time-driven activity-based costing to estimate annualised costs associated with typical diabetes care in Chiapas, Mexico, as well as a novel diabetes care model known as Compañeros En Salud Programa de Enfermedades Crónicas (CESPEC). We conducted Markov chain analysis to estimate the costeffectiveness of CESPEC compared with usual care from a societal perspective. We used patient outcomes from CESPEC in 2016, as well as secondary data from existing literature.

Setting Rural primary care clinics in Chiapas, Mexico.

Participants Adults with diabetes.

Interventions CESPEC is a novel, comprehensive, diabetes care model that integrates community health workers, provider education, supply chain management and active case finding.

Outcome measure The primary outcome was the incremental cost-effectiveness of CESPEC compared with care as usual, per quality-adjusted life year (QALY) gained, expressed in 2016 US dollars.

Results The economic cost of the CESPEC diabetes model was US\$144 per patient per year, compared with US\$125 for diabetes care as usual. However, CESPEC care was associated with 0.13 additional years of healthadjusted life expectancy compared with usual care and 0.02 additional years in the first 5 years of treatment. This translated to an incremental cost-effectiveness ratio (ICER) of US\$2981 per QALY gained over a patient's lifetime and an ICER of US\$10 444 over the first 5 years. Findings were robust to multiple sensitivity analyses.

Conclusions CESPEC is a cost-effective, communitybased model of diabetes care for patients in rural Mexico. Given the high prevalence and significant morbidity associated with diabetes in Mexico and other countries in Central America, this model should be considered for broader scale up and evaluation.
Strengths and limitations of this study

- This economic evaluation studied a novel, community-based diabetes care model (Compañeros En Salud Programa de Enfermedades Crónicas (CESPEC)) in a rural low-income and middle-income country, a setting in which few economic evaluations exist, despite a high burden of diabetes in rural areas.

- We conducted detailed cost analysis using a rigorous time-driven activity-based costing approach.

- Findings of cost-effectiveness of CESPEC were from a societal perspective and were robust to two different time horizons and multiple sensitivity analyses.

- Limitations include: (1) using simplifying assumptions in the decision analysis model that likely generated conservative estimates of cost-effectiveness and (2) a limited geographic scope that tempers generalisability of our findings and warrants additional evaluation in other settings.

\section{INTRODUCTION}

Diabetes continues to rise as a leading cause of disability and mortality in the world and now ranks as the 12th leading cause of disabilityadjusted life years (DALYs) worldwide. ${ }^{1}$ There are an estimated 422 million patients in the world currently living with diabetes and 3.7 million diabetes-related deaths per year. $^{2}$ The growing medical burden comes with concomitant economic costs. By some estimates, the yearly global cost of diabetes is US $\$ 1.31$ trillion. ${ }^{3}$ In Mexico, where diabetes is the leading cause of DALYs and affects over 11.5 million adults, ${ }^{4-6}$ associated costs are rapidly increasing, currently representing $15 \%$ of total health expenditure. ${ }^{6-8}$

Innovative, low cost models of diabetes care are needed to address the worsening health and economic challenges driven by diabetes. 
Most existing cost-effectiveness studies in diabetes care are focused on narrow therapeutic interventions, as opposed to comprehensive models of care. ${ }^{9}$ This is despite the fact that international society guidelines emphasise multicomponent, interdisciplinary care models, with modest evidence available supporting cost-effectiveness. ${ }^{10-14}$ The evaluation of multicomponent diabetes care models in low-income and middle-income countries (LMICs) such as Mexico is limited, particularly evaluations that use economic analysis as a tool to assess the value of a largescale investment to restructure care.

We assessed the cost and cost-effectiveness of a novel chronic disease management programme for diabetes care in rural Chiapas, Mexico, called the Compañeros En Salud Programa de Enfermedades Crónicas (CESPEC). We previously described the programme's implementation and quantified its clinical effectiveness for improving diabetes and hypertension control, using thresholds set by the Secretariat of Health of Chiapas (SSCH in Spanish) as a haemoglobin A1c below 7\% and a blood pressure $<140 / 90 \mathrm{~mm} \mathrm{Hg} .{ }^{15}$ In this study, we performed an economic evaluation of CESPEC to: (1) estimate the annualised economic cost per patient with diabetes relative to the cost of care as usual and (2) estimate the incremental cost-effectiveness of CESPEC relative to care as usual, measured as cost per quality-adjusted life years (QALYs) gained. We hypothesised that CESPEC would be cost-effective when compared with a standard threshold of three times the national gross domestic product (GDP) per capita in Mexico ${ }^{16}$ and when compared with other cost-effective diabetes interventions catalogued in the literature. ${ }^{1718}$

\section{METHODS}

\section{Setting}

Compañeros En Salud (CES) is the Mexico-based affiliate of Partners In Health, a non-governmental healthcare delivery organisation. Since 2011, CES has focused on health system strengthening and the provision of comprehensive primary care in rural Chiapas. Chiapas is one of the poorest states in Mexico and has the third lowest life expectancy in the country. ${ }^{19}{ }^{20}$ Similar to the rest of Mexico, diabetes is the greatest cause of combined death and disability in the state. ${ }^{21}$

CES operates primary care clinics in 10 rural communities in the Sierra Madre region of the state, serving as the primary source of healthcare. CES runs in collaboration with the SSCH, and the clinics are integrated into the broader public healthcare system. In other rural regions of Chiapas not supported by CES, the SSCH operates rural clinics directly. Both CES and non-CES communities share similar socioeconomic conditions, and additional details regarding the setting and socioeconomic comparisons are described elsewhere. ${ }^{15}$

\section{Diabetes treatment models}

We evaluated and compared two treatment models for the management of type 2 diabetes. First, we studied usual care at rural clinics run directly by the SSCH. Usual diabetes care at SSCH clinics consists of monthly, routine medical examinations with a general medical provider and nurse. Any medications prescribed during the visit are dispensed on-site through a pharmacy at no cost to the patient, subsidised by the SSCH. In this model, there are no additional resources or health education sessions outside of regular clinic visits.

The second model evaluated was CESPEC, a community-based non-communicable disease management programme started in 2014 by CES. The programme consists of: (1) household engagement by community health workers (CHWs), (2) provider education and support, including evidenced-based algorithms to support decision making, (3) supplemental supply chain management to procure medicines that previously suffered frequent stockouts and (4) active case finding in the community. For diabetes care, the CESPEC model involves monthly clinic visits with a physician who is completing a government-required social service year (pasante) before obtaining a full medical licence. Between clinic visits, additional patient teaching and follow-up is provided by CHWs depending on patient history of diabetes control. CHWs act as a liaison between the clinic and the patient, providing education, psychosocial support and medication adherence reinforcement. They are nominated by the community and compensated with food/consumable items. Communities also undergo regular screening with an active case-finding programme that occurs biannually. The design, implementation and clinical effectiveness of CESPEC has been previously published. ${ }^{15}$ Detailed process maps of the two comparative care delivery models are available in figure 1.

\section{Cost analysis}

We used time-driven activity-based costing (TDABC) to estimate the costs of both CESPEC and usual care. ${ }^{22-24}$ TDABC involves determining the costs of the healthcare by directly observing patient flow through a health system, and assigning costs to each activity in a cycle of care based on activity duration and resources used, such as personnel, equipment and clinic space. We identified all activities related to diabetes care, as well as duration of each activity, through key informant interviews with medical personnel and direct observation of patients receiving care in August-December 2016. We adopted a societal perspective and included the opportunity cost of all involved individuals (including patients). Staff time was valued at full salary cost, including benefits. The cost of volunteered time at CES was estimated based on the salary of staff in similar, paid roles. We estimated the opportunity cost of patient time using local wages in Chiapas. ${ }^{19}$

Direct costs incurred by CESPEC were obtained from the organisational budget and price lists from actual 


\section{A}

Annual diabetes care process

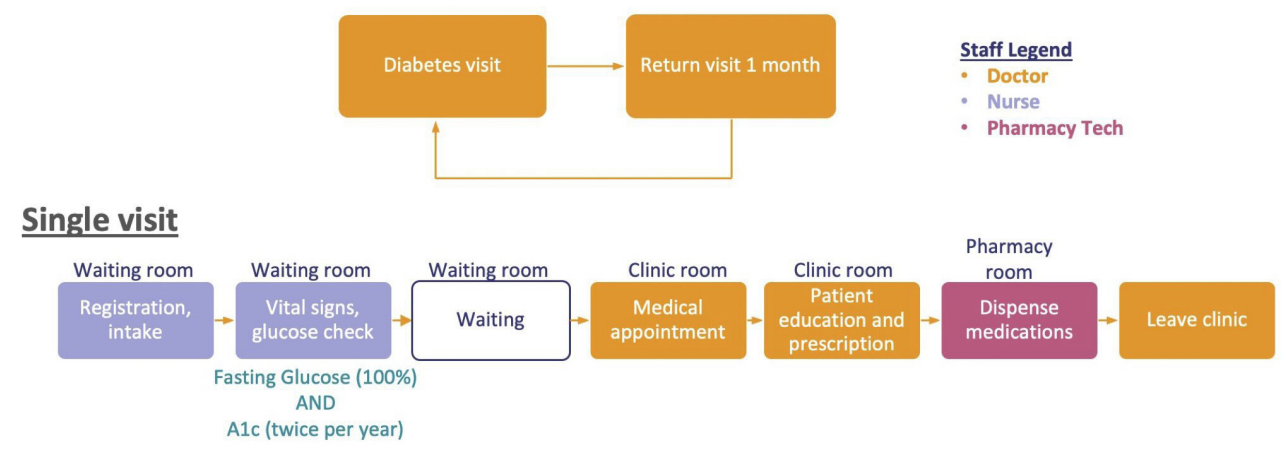

B

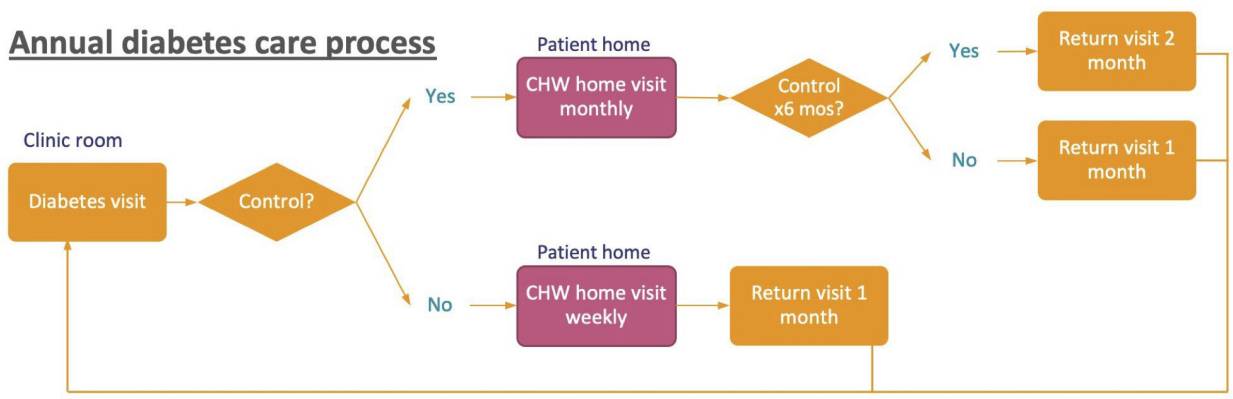

Single visit

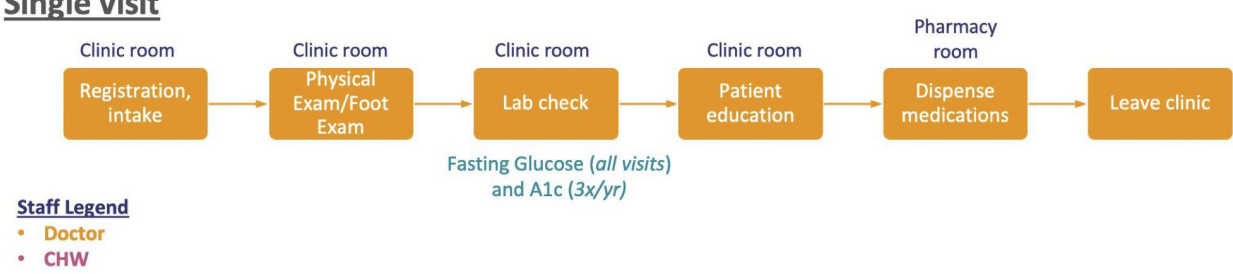

Figure 1 Diabetes care process maps. (A) Diabetes care process maps for usual care. (B) Diabetes care process maps for CESPEC. CESPEC, Compañeros En Salud Programa de Enfermedades Crónicas; CHW, community health worker.

vendors. Costs for medications and labour for the SSCH clinics were obtained from multiple publicly available government pricing lists. ${ }^{25}{ }^{26}$ We assumed $100 \%$ medication adherence with no stockouts. We estimated the cost of physical space based on area construction costs for equivalent square footage and assumed 20-year linear depreciation of physical space. For indirect costs, we calculated CES-related administration and overhead costs associated with operating the NGO. Central, state-level administrative costs were excluded from indirect cost calculations.

Our primary cost analysis outcome was the economic cost of diabetes care per patient per year in 2016 US dollars. We chose 2016 as the year of analysis since that is when direct field observations occurred and the year in which we collected CES budget information. We chose to report results in US dollars for general interpretability and because many cost inputs were obtained in this currency. Costs that were obtained as Mexican pesos were converted to US dollars based on 2016 exchange rates. ${ }^{27}$ Any costs obtained from other years were inflation adjusted to 2016 using the Mexican Consumer Price Index. ${ }^{28} 29$

\section{Cost-effectiveness analysis}

We estimated incremental cost-effectiveness ratios using a Markov modelling approach in TreeAge Pro Healthcare 2020 (Williamstown, Massachusetts, USA). The decision analysis model accounted for diabetes control rates for CESPEC and usual care and their relationships to longterm health outcomes and diabetes-related complications (see online supplemental appendix figure 1 for a schematic of the decision tree). The Markov cycle duration was 1 year, and we assumed a treatment effect of CESPEC for only 1 year. That is, the status of diabetes control could change from controlled to uncontrolled or vice versa in any subsequent Markov cycle. The model quantified probabilities and morbidity associated with microvascular complications (nephropathy, retinopathy and neuropathy) and macrovascular complications (stroke and 
myocardial infarction), making two simplifying assumptions. First, we conservatively assumed microvascular complications were permanent and mutually exclusive. Second, we also assumed macrovascular complications were transient events that could recur and did not result in long-term sequelae. In our base case scenario, we adopted a lifetime analytical horizon. We also modelled an additional time horizon of 5 years to evaluate short-term incremental cost-effectiveness of CESPEC relative to care as usual. The patient cohort entered the Markov model at age 40 years, given the rapid rise in diabetes incidence that occurs around age 40 years in Chiapas, as reported in Global Burden of Disease data. ${ }^{30}$ We employed a halfcycle correction in Markov models and incorporated a global discount rate of 3\% for both cost and QALYs. ${ }^{16} 17$

For cost estimates in the models, we used the parameters identified from our cost analysis as inputs for the annual cost of diabetes care under the usual care and CESPEC models. Other model parameters were drawn from existing literature, considering the recency, quality and appropriateness of studies. For the costs of complications, we used national estimates from Mexico as reported by Fundación Mexicana para la Salud. ${ }^{31}$ Other studies evaluating costs in Mexico either do not provide separate estimates of individual complications or provide aggregate population costs instead of a per patient annual cost. ${ }^{32}$ Transition probability inputs were obtained from the existing literature. Where possible, we selected high-quality studies from Mexican populations. Otherwise, we selected the best available studies with detailed assessment of complications based on disease control. We derived health-adjusted quality of life inputs for disease states using the inverse of disability weights from the 2016 Global Burden of Disease study. ${ }^{33} 34$ A detailed discussion of study selection, methods and a table of model parameters is available in the online supplemental appendix.

Our primary outcome for cost-effectiveness analyses was the incremental cost-effectiveness ratio (ICER) per QALY gained for the base case scenario. We chose QALYs instead of DALYs as our primary outcome as an established and accepted measure used by policymakers to assess intervention cost-effectiveness. We considered an ICER less than three times 2016 GDP per capita in Mexico (US\$26 219.28) ${ }^{35}$ to be cost-effective, based on established guidelines. ${ }^{16}$ ICERs less than one time the GDP per capita (US\$8739.76) were considered very cost-effective. We acknowledge that a fixed GDP-based threshold fails to incorporate local context and competing health policy priorities in determining cost-effectiveness, ${ }^{18}$ and we therefore also qualitatively evaluated the ICERs compared with ICERS of similar interventions, reflected in the discussion section.

We performed sensitivity analyses to assess the effect of input parameter uncertainty on our cost-effectiveness estimates. First, we performed one-way deterministic sensitivity analyses by varying individual input parameters. Specifically, we varied programme cost estimates and diabetes control probability from $80 \%$ to $120 \%$ of point estimate values for both CESPEC and usual care. We also varied the costs of complications from $80 \%$ to $120 \%$. Second, we performed a scenario-based deterministic sensitivity analysis, in which we assumed all medical providers in CESPEC were general medical providers instead of pasantes, as pasantes are paid significantly less. Third, we performed probabilistic sensitivity analysis by varying all model parameters simultaneously by sampling from their respective distributions (online supplemental appendix table 1) following a Monte Carlo approach with 10000 simulations. We assessed that 10000 simulations was sufficient to produce stable results by testing for model convergence. ${ }^{36}$

\section{Patient and public involvement}

There was no patient or public involvement in the design, conduct, reporting or dissemination of this study.

\section{RESULTS}

\section{Cost analysis}

The cost of usual care at SSCH clinics in 2016 was US $\$ 125$ per patient per year. This estimate was based on US\$99 in visit costs and $\$ 26$ in medication costs. The per visit cost was US\$8.25, of which personnel accounted for $89 \%$ of per visit costs, followed by resources at $7 \%$ and physical space at $4 \%$ of per visit cost (table 1 ).

CESPEC services cost US $\$ 144$ per patient per year. Visits only accounted for $32 \%$ of total CESPEC costs, compared with $79 \%$ in usual care, because CESPEC relies primarily on pasantes for service delivery. CESPEC also incurred an additional US $\$ 53.26$ per patient per year of indirect costs, including general administrative costs (US\$12.31), coordinating CHWs (US\$34.24) and active case finding (US\$6.71). The per visit cost was US\$4.02, again primarily driven by personnel that accounted for $90 \%$ of the per visit cost, followed by resources at $16 \%$ and physical space at $4 \%$ of per visit cost. The opportunity cost for a patient to participate in a visit was estimated at US\$0.96 in lost wages.

\section{Cost-effectiveness analysis}

Based on the health states and transition probabilities associated with CESPEC and care as usual, estimated gains in health-adjusted life expectancy for CESPEC recipients was 15.40 , compared with 15.26 among individuals receiving care as usual. Limited to the first 5 years of treatment, gains in health-adjusted years were 4.15 for CESPEC recipients and 4.13 among recipients of care as usual (table 2).

Under the base case scenario of a lifetime time horizon, we estimated an ICER for CESPEC of US $\$ 2981$ per QALY gained, which is considered very cost-effective insofar as this is below Mexico's GDP per capita (US\$8739.76). Under a 5-year time horizon, the ICER for CESPEC remained cost-effective at US\$10 444 per QALY gained. 
Table 1 Cost analysis results

\begin{tabular}{|c|c|c|}
\hline Cost element & $\begin{array}{l}\text { Usual care } \\
\text { (2016 US\$) }\end{array}$ & $\begin{array}{l}\text { CESPEC } \\
\text { (2016 } \\
\text { US\$) }\end{array}$ \\
\hline Per visit per patient & $\$ 8.25$ & $\$ 4.02$ \\
\hline Personnel & $\$ 7.32$ & $\$ 3.24$ \\
\hline Patient & $\$ 2.23$ & $\$ 0.96$ \\
\hline Medical provider & $\$ 3.75$ & $\$ 1.04$ \\
\hline Nurse & $\$ 1.13$ & $N / A^{*}$ \\
\hline Pharmacy technician & $\$ 0.21$ & $N / A^{*}$ \\
\hline Clinical supervisor & $N / A^{*}$ & $\$ 1.24$ \\
\hline Resources & $\$ 0.63$ & $\$ 0.63$ \\
\hline Lab equipment & $\$ 0.00 \dagger$ & $\$ 0.00 \dagger$ \\
\hline Lab reagents/test strips & $\$ 0.63$ & $\$ 0.63$ \\
\hline Clinic space & $\$ 0.30$ & $\$ 0.15$ \\
\hline Waiting room & $\$ 0.22$ & $\$ 0.04$ \\
\hline Clinic room & $\$ 0.06$ & $\$ 0.09$ \\
\hline Pharmacy area & $\$ 0.02$ & $\$ 0.02$ \\
\hline Nurse area & $\$ 0.00 \dagger$ & $N / A^{*}$ \\
\hline \multicolumn{3}{|l|}{ Per patient per year } \\
\hline Visits & $\$ 99.04$ & $\$ 45.74$ \\
\hline Medications & $\$ 25.79$ & $\$ 44.69$ \\
\hline Indirect costs & N/A & $\$ 53.26$ \\
\hline Total cost per patient per year & $\$ 124.83$ & $\$ 143.69$ \\
\hline
\end{tabular}

${ }^{*}$ Cost element was not a part of this particular care model.

†The per visit per patient cost of this cost element was estimated to be less than 1 US cent.

$\mp$ Centralised state-level administrative costs were assumed to be the same across both CESPEC and usual care and excluded from the analysis.

CESPEC, Compañeros En Salud Programa de Enfermedades Crónicas.

\section{Sensitivity analysis}

One-way sensitivity analyses demonstrated that CESPEC remained very cost-effective despite varying multiple parameters from $80 \%$ to $120 \%$ of their point estimates (figure 2). The ICER for CESPEC was most sensitive to changes in the estimated programme cost of CESPEC, which varied from CESPEC dominating usual care to an ICER of US\$6346 per QALY gained (online supplemental appendix table 2). In the scenario under which we assumed that all providers in CESPEC were higher paid general medical providers (not pasantes), we input a CESPEC programme cost of $\$ 232$ per patient per year. We calculated an ICER of US $\$ 13509$ per QALY gained in this scenario, again considered costeffective at the threshold of three times national GPD per capita. In the probabilistic sensitivity analysis, we calculated a mean ICER of US\$3770.33 (table 2). CESPEC was cost-effective in $83 \%$ of scenarios at the willingness-to-pay of three times GDP per capita (figure 3). We confirmed that our model converged and produced stable probabilistic sensitivity analysis results after 10000 simulations, as the mean incremental net monetary benefit $95 \%$ CI did not include zero (table 2 ). ${ }^{36}$

\section{DISCUSSION}

In this economic evaluation of two diabetes care models in rural Chiapas, Mexico, we found that the novel CESPEC model of care provides high-value, cost-effective diabetes care relative to care as usual. We estimated that CESPEC costs US\$2940 per QALY gained when viewed over an individual's lifespan. The estimated ICER is similar to other ICERs in high-income countries for diabetes education and multicomponent interventions that have a median cost in the range of US\$2315-US\$5047 per QALY gained. ${ }^{14}$ Locally, estimates from Mexico suggest that intensively controlling diabetes would cost US $\$ 12,500-$ US\$16900 per QALY gained. ${ }^{37}$ CESPEC compares favourably with these existing estimates from the literature. Using GDP-based ICER thresholds, ${ }^{16}$ CESPEC is considered very cost-effective and remains cost-effective even when limited to the first 5 years of treatment. To our knowledge, this is the first study measuring the economic value of a rural comprehensive diabetes management programme in an LMIC. ${ }^{38}$

Our cost analysis found that CESPEC is more expensive compared with usual care within SSCH clinic. This is primarily due to indirect costs associated with CESPEC care delivery. CESPEC requires additional personnel and resources for all four components of the programme, including provider education, supply chain management, CHWs and active case finding. While these four components generate additional costs, they do not exist in usual care and are the high-value interventions that underly the clinical effectiveness of CESPEC in improving diabetes control. We posit that the CHW model and supply chain management components are particularly important, as previous research in rural Chiapas indicates a lack of trust in centralised health systems and supply shortages in medicines that undermine patient engagement. ${ }^{39}$ Further work is needed to study the value of each CESPEC component individually and to determine whether they are additive or synergistic when combined.

The CESPEC care delivery model remained costeffective in the context of multiple sensitivity analyses. This is particularly important because clinics using the CESPEC model are staffed exclusively by pasante physicians that are lower cost than typical licenced medical providers. By contrast, SSCH clinics that deliver standard care are usually staffed by non-pasantes. Our findings indicate that, even if CESPEC were staffed entirely by non-pasantes, it would remain cost-effective. This lends greater external validity to our cost-effectiveness findings as a potential model for scale up in other rural regions of Mexico.

Our findings have significant policy implications. In 2016, the Mexican government declared diabetes as a 
Table 2 Cost-effectiveness analysis results

$\begin{array}{llllll}\text { Costs per } & \text { QALYs per } & \text { Incremental costs } & \text { Incremental } & & \\ \text { person } & \text { person } & \text { per person } & \text { QALYs per } & \text { ICER } & \text { INMB* }^{*} \\ \text { (2016 US\$) } & \text { (2016 US\$) } & \text { (2016 US\$) } & \text { person } & \text { (2016 US\$) } & \text { (2016 US\$) }\end{array}$

\begin{tabular}{|c|c|c|c|c|c|c|}
\hline \multicolumn{7}{|c|}{ Base case (lifetime time horizon) } \\
\hline Usual care & $\$ 12044.99$ & 15.26 & Ref & Ref & Ref & Ref \\
\hline CESPEC & $\$ 12440.76$ & 15.40 & $\$ 395.77$ & 0.13 & $\$ 2981.49$ & $\$ 3084.65$ \\
\hline \multicolumn{7}{|c|}{ 5-year time horizon } \\
\hline Usual care & $\$ 1413.31$ & 4.13 & Ref & Ref & Ref & Ref \\
\hline CESPEC & $\$ 1575.39$ & 4.15 & $\$ 162.08$ & 0.02 & $\$ 10444.29$ & $\$ 3477.78$ \\
\hline \multicolumn{7}{|c|}{ Probabilistic sensitivity analysis $†$} \\
\hline Usual care & $\$ 11801.34$ & 15.35 & Ref & Ref & Ref & Ref \\
\hline CESPEC & $\$ 12274.86$ & 15.48 & $\$ 473.52$ & 0.13 & $\$ 3770.33 \ddagger$ & $\begin{array}{l}\$ 2819.38 \\
\text { (95\% Cl \$2758 to \$2881) }\end{array}$ \\
\hline
\end{tabular}

*INMB calculated using a willingness-to-pay threshold of US\$26219.28 (three times the gross domestic product per capita in Mexico). †Outcomes reported are means of 10000 Monte Carlo simulations.

$\ddagger 95 \% \mathrm{CI}$ not calculated for the ICER due to the challenge in calculating variance of a ratio of two variables. Instead, cost-effectiveness acceptability curves are presented elsewhere per CHEERS guidelines. ${ }^{47}$

CESPEC, Compañeros En Salud Programa de Enfermedades Crónicas; ICER, incremental cost-effectiveness ratio; INMB, incremental net monetary benefit; QALY, quality-adjusted life year.

national public health emergency, devoting political and financial resources towards the prevention, identification and treatment of the disease. ${ }^{40}$ Many public and private programmes have been launched in an effort to tackle the diabetes epidemic in Mexico, ${ }^{41}$ but rigorous evidence of programme effectiveness or economic value is limited. Furthermore, none of these existing programmes is focused on rural populations, despite a high prevalence of diabetes in both urban and rural Mexico. ${ }^{42}$ Delivering high-quality diabetes care to rural populations is critical as these groups face additional barriers in access to care $^{43}$ and suffer more catastrophic health expenditures compared with urban populations. ${ }^{44}$ CESPEC offers a clinically effective and high-value model of diabetes care for rural settings that can be achieved with targeted investments. All CES clinics operate within the existing public health infrastructure and do not operate as a parallel system. As such, CESPEC as a whole, or its key components, could supplement the existing public health system by improving health services delivered to historically marginalised communities without needing significant structural change. ${ }^{39}$ In addition, our modelling of different time horizons found that CESPEC is costeffective even on a short time horizon, which highlights

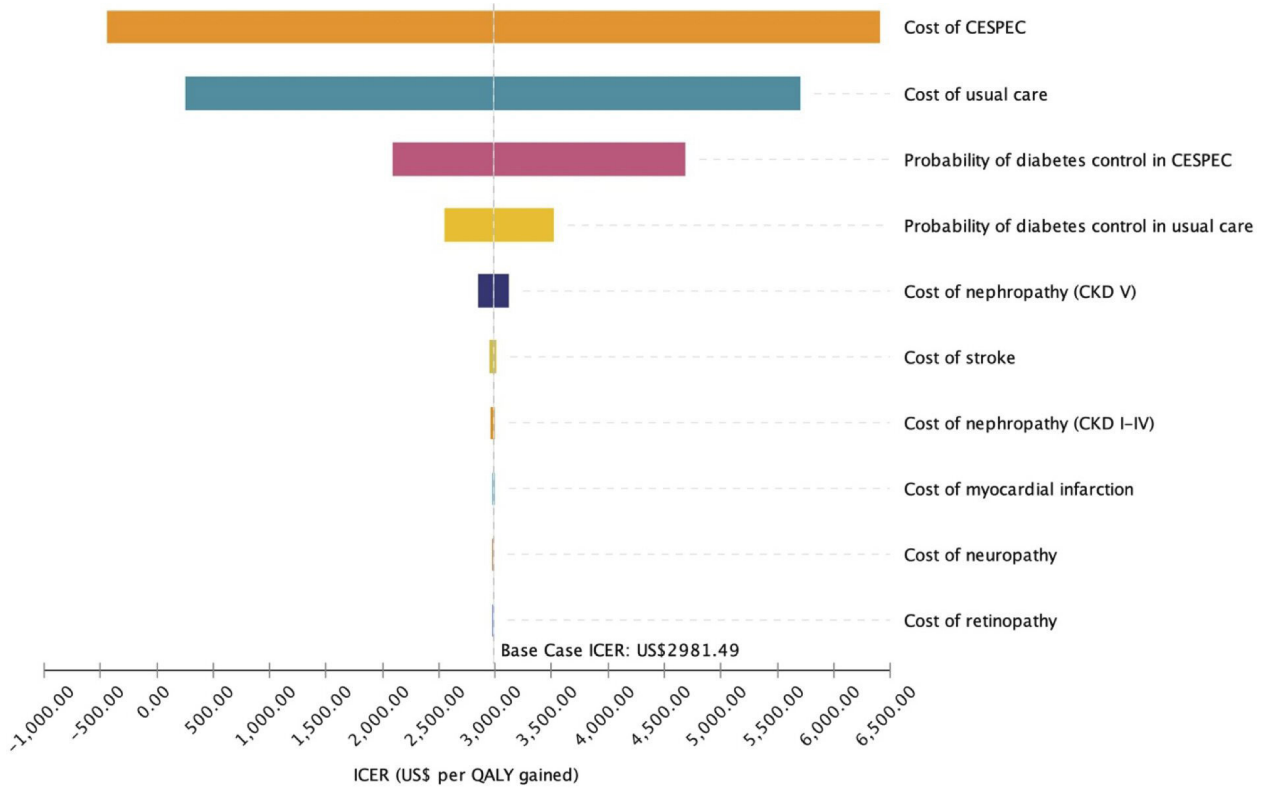

Figure 2 One-way deterministic sensitivity analysis results. CKD, chronic kidney disease; CESPEC,Compañeros En Salud Programa de Enfermedades Crónicas; ICER, incrementalcost-effectiveness ratio; QALY, quality-adjusted life year. 


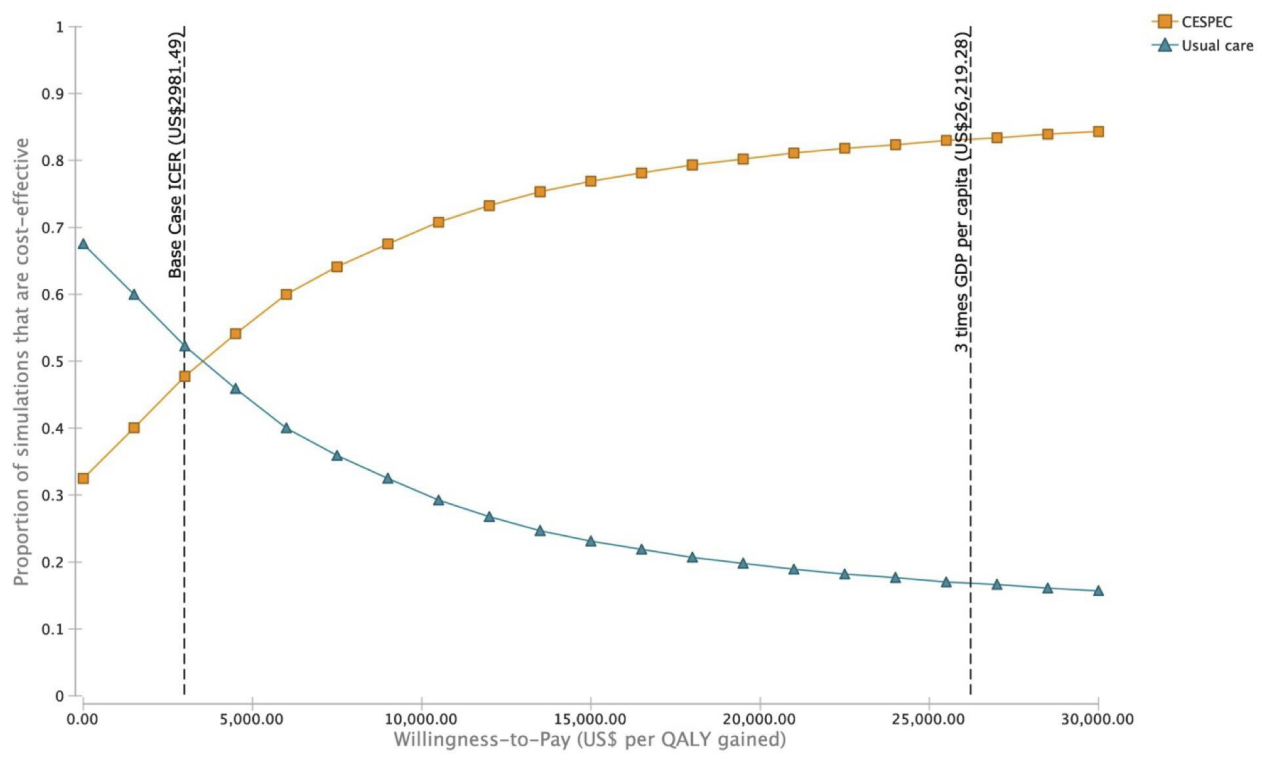

Figure 3 Probabilistic sensitivity analysis acceptability curve. CESPEC,Compañeros En Salud Programa de Enfermedades Crónicas; ICER, incrementalcost-effectiveness ratio; GDP, gross domestic product; QALY, quality-adjusted life year.

the potential for this model to make an immediate impact in efforts to improve population health. Further study is needed to test the generalisability and scalability of CESPEC in other rural regions, especially given the heterogeneous populations throughout rural Mexico. ${ }^{45}$ Efforts to scale CESPEC should also consider how the model would interface differently with each of Mexico's separately administered and financed public healthcare systems.

This study has several limitations. First, we used population-level data inputs for the Markov model. While valuable for policy decisions, a patient-level microsimulation approach may provide more precise estimates. This technique requires more granular data than were available for our study. Second, we made simplifying assumptions in our decision tree for the purposes of constructing the model, such as limiting the number of microvascular complications a patient could develop. However, we know from clinical experience that patients can suffer multiple complications from diabetes simultaneously. ${ }^{46}$ Therefore, we expect that the ICER estimates in this study are likely conservative and may represent an upper bound. Third, one of the key parameters that differed between CESPEC and usual care was the probability of diabetes control. We used 1 year diabetes control figures based on previously identified estimates, ${ }^{15}$ but diabetes control figures greater than 1 year would provide more confidence in our estimates. This limitation was mitigated using sensitivity analyses to vary estimates of assumed clinical effectiveness. Fourth, we ascertained the duration of each activity for TDABC at 4 of 10 CES communities but only one usual care SSCH clinic. We accounted for this uncertainty with multiple sensitivity analyses. Fifth, we made the simplifying assumption that utility weights are equivalent to the inverse of disability weights due to limitations in utility weight data availability in LMICs. Based on past analyses examining both QALYs and DALYs, the resulting estimates are unlikely to meaningfully change the overall interpretation. ${ }^{34}$ Sixth, many of our transition probabilities were derived from studies in high-income countries since estimates were not available from Mexican settings. These transition probabilities may differ from those of Mexican patients and could influence our results. Despite these limitations, our study has significant strengths, including a societal cost perspective taking into account opportunity cost of patients, a rigorous TDABC costing approach, a Markovian framework for cost-effectiveness analysis with multiple time horizons and three sensitivity analyses to strengthen confidence in our estimates.

\section{CONCLUSION}

CESPEC is a novel and high-value diabetes care model in rural Mexico that focuses on community engagement, continuing medical education to health workers and community members, supply chain management and active case finding. The programme costs $\$ 144$ per patient per year and is highly cost-effective at US\$2981 per QALY gained. Further study is needed to evaluate whether CESPEC can be successfully scaled and evaluated in other rural regions of Mexico.

\section{Author affiliations}

${ }^{1}$ Division of Pulmonary, Critical Care and Sleep Medicine, University of Washington, Seattle, Washington, USA

${ }^{2}$ Last Mile Health, Boston, Massachusetts, USA

${ }^{3}$ Division of Global Health Equity, Brigham and Women's Hospital, Boston, Massachusetts, USA

${ }^{4}$ Compañeros en Salud/Partners In Health Mexico, Ángel Albino Corzo, Chiapas, Mexico

${ }^{5}$ Harvard Medical School, Boston, Massachusetts, USA

${ }^{6}$ Partners In Health, Boston, Massachusetts, USA

${ }^{7}$ London School of Hygiene \& Tropical Medicine, London, UK

${ }^{8}$ Royal Darwin Hospital, Casuarina, Darwin, Australia 
${ }^{9}$ Instituto de Salud del Estado de Chiapas, Tuxtla Gutiérrez, Chiapas, Mexico ${ }^{10}$ National School of Nursing and Obstetrics, National Autonomous University of Mexico, Mexico City, Mexico

${ }^{11}$ RAND Corp Boston Office, Boston, Massachusetts, USA

\section{Twitter Luis Alberto Martinez-Juarez @luismartts}

Acknowledgements We would like to thank the entire team at Compañeros En Salud for their contributions to this work and their care of patients with chronic diseases in the Sierra Madre region of Chiapas, Mexico. We would also like to thank the staff at the Jaltenango Secretariat of Health of Chiapas clinic for their assistance with this study.

Contributors KID, HF, DP, PFE, LP and RKM conceived and designed the study. All authors contributed to the acquisition, analysis or interpretation of data for the work. KID and RKM drafted the manuscript. All authors critically revised the manuscript and approved the final version. All authors authors agree to be accountable for all aspects of the work.

Funding This work was supported by a grant from the US National Institutes of Health (T32HL007287) to KID. The dissemination of this work as Open Access was supported by a grant from the AbbVie Foundation.

Disclaimer Funders had no role in study design, data collection, analysis or manuscript preparation.

Competing interests DP receives funding from Last Mile Health as a consultant to the Community Health Academy.

Patient consent for publication Not required.

Ethics approval The study was approved by the Partners Healthcare Institutional Review Board in Boston, Massachusetts (2017P000401/PHS), and deemed exempt due to the retrospective evaluation of existing data in a de-identified format. It was also approved by the Bioethics Committee of the State of Chiapas, Mexico (Oficio \#5003/1763).

Provenance and peer review Not commissioned; externally peer reviewed.

Data availability statement № data are available as they include sensitive salary data.

Supplemental material This content has been supplied by the author(s). It has not been vetted by BMJ Publishing Group Limited (BMJ) and may not have been peer-reviewed. Any opinions or recommendations discussed are solely those of the author(s) and are not endorsed by BMJ. BMJ disclaims all liability and responsibility arising from any reliance placed on the content. Where the content includes any translated material, BMJ does not warrant the accuracy and reliability of the translations (including but not limited to local regulations, clinical guidelines, terminology, drug names and drug dosages), and is not responsible for any error and/or omissions arising from translation and adaptation or otherwise.

Open access This is an open access article distributed in accordance with the Creative Commons Attribution Non Commercial (CC BY-NC 4.0) license, which permits others to distribute, remix, adapt, build upon this work non-commercially, and license their derivative works on different terms, provided the original work is properly cited, appropriate credit is given, any changes made indicated, and the use is non-commercial. See: http://creativecommons.org/licenses/by-nc/4.0/.

\section{ORCID iDs}

Kevin I Duan http://orcid.org/0000-0002-8542-6611

Luis Alberto Martinez-Juarez http://orcid.org/0000-0001-7550-7867

\section{REFERENCES}

1 Abajobir AA, Abate KH, Abbafati C. Global, regional, and national disability-adjusted life-years (DALYs) for 333 diseases and injuries and healthy life expectancy (HALE) for 195 countries and territories, 1990-2016: a systematic analysis for the global burden of disease study 2016. Lancet 2017;390:1260-344.

2 Roglic G. Global report on diabetes. World Health Organization, 2016.

3 Bommer C, Heesemann E, Sagalova V, et al. The global economic burden of diabetes in adults aged $20-79$ years: a cost-of-illness study. Lancet Diabetes Endocrinol 2017;5:423-30.

4 Institute for Health Metrics and Evaluation. Mexico country profile. Available: http://www.healthdata.org/mexico [Accessed 23 Mar 2017].
5 Kassebaum NJ, Arora M, Barber RM, et al. Global, regional, and national disability-adjusted life-years (DALYs) for 315 diseases and injuries and healthy life expectancy (HALE), 1990-2015: a systematic analysis for the global burden of disease study 2015. Lancet 2016;388:1603-58.

6 International Diabetes Federation. IDF diabetes atlas. International Diabetes Federation, 2015.

7 Arredondo A, De Icaza E. Costos de la diabetes en Ameŕica Latina: Evidencias del Caso Mexicano. Value in Health 2011;14:S85-8.

8 Zhang P, Zhang X, Brown J, et al. Global healthcare expenditure on diabetes for 2010 and 2030. Diabetes Res Clin Pract 2010;87:293-301.

9 Li R, Zhang P, Barker LE, et al. Cost-Effectiveness of interventions to prevent and control diabetes mellitus: a systematic review. Diabetes Care 2010;33:1872-94.

10 International Diabetes Federation Guideline Development Group. Global guideline for type 2 diabetes. Diabetes Res Clin Pract 2014;104:1-52.

11 Kuo S, Bryce CL, Zgibor JC, et al. Cost-Effectiveness of implementing the chronic care model for diabetes care in a military population. J Diabetes Sci Technol 2011;5:501-13.

12 Gilmer TP, Roze S, Valentine WJ, et al. Cost-effectiveness of diabetes case management for low-income populations. Health Serv Res 2007;42:1943-59.

13 Mason JM, Freemantle N, Gibson JM, et al. Specialist nurse-led clinics to improve control of hypertension and hyperlipidemia in diabetes: economic analysis of the SPLINT trial. Diabetes Care 2005;28:40-6.

14 Siegel KR, Ali MK, Zhou X, et al. Cost-effectiveness of interventions to manage diabetes: has the evidence changed since 2008 ? Diabetes Care 2020;43:1557-92.

15 Duan K, McBain R, Flores $\mathrm{H}$, et al. Implementation and clinical effectiveness of a community-based non-communicable disease treatment programme in rural Mexico: a difference-in-differences analysis. Health Policy Plan 2018;33:707-14.

16 World Health Organization. Cost effectiveness and strategic planning (WHO-CHOICE). who. Available: https://www.who.int/choice/costeffectiveness/en/ [Accessed August 14, 2020].

17 Sanders GD, Neumann PJ, Basu A, et al. Recommendations for conduct, methodological practices, and reporting of costeffectiveness analyses: second panel on cost-effectiveness in health and medicine. JAMA 2016;316:1093.

18 Marseille E, Larson B, Kazi DS, et al. Thresholds for the costeffectiveness of interventions: alternative approaches. Bull World Health Organ 2015;93:118-24.

19 OECD. Measuring well-being in Mexican states. OECD Publishing, 2015.

20 GHDx. Institute for health metrics and evaluation global burden of disease results tool. Available: http://ghdx.healthdata.org/gbdresults-tool [Accessed 19 Aug 2020].

21 Institute for Health Metrics and Evaluation. Mexico - Chiapas Country Profile. Available: http://www.healthdata.org/mexico-chiapas [Accessed 27 Nov 2017].

22 McBain RK, Jerome G, Warsh J, et al. Rethinking the cost of healthcare in low-resource settings: the value of time-driven activitybased costing. BMJ Glob Health 2016;1:e000134.

23 Kaplan RS, Witkowski M, Abbott M, et al. Using time-driven activity-based costing to identify value improvement opportunities in healthcare. J Healthc Manag 2014;59:399-412.

24 Kaplan RS, Anderson SR. Time-driven activity-based costing. Harv Bus Rev 2004;82:131-8.

25 Diario Oficial de la Federación. Precios de Referencia. Available: http://www.dof.gob.mx/nota_detalle.php?codigo=5443837\&fecha= 07/07/2016 [Accessed 27 Nov 2017].

26 Secretaría de Salud. Biblioteca virtual DGPLADES. Available: https:// www.gob.mx/salud/acciones-y-programas/biblioteca-virtualdgplades [Accessed 27 Nov 2017].

27 Internal Revenue Service. Yearly average currency exchange rates. Available: https://www.irs.gov/individuals/international-taxpayers/ yearly-average-currency-exchange-rates [Accessed 20 Aug 2020].

28 Dunn A, Grosse SD, Zuvekas SH. Adjusting health expenditures for inflation: a review of measures for health services research in the United States. Health Serv Res 2018:53:175-96.

29 The World Bank. Consumer price index - Mexico | Data. Available: https://data. worldbank.org/indicator/FP.CPI.TOTL?end=2019\& locations=MX\&name_desc $=$ false\&start=2000 [Accessed 9 Feb 2021]

30 Institute for Health Metrics and Evaluation. GBD compare | IHME viz hub. Available: http://vizhub.healthdata.org/gbd-compare [Accessed 14 Feb 2021]

31 Barraza Lloréns M, Barrón G V, Picó J. Carga Económica de La Diabetes Mellitus En México, 2013. Funsalud, 2015. Available: 
https://funsalud.org.mx/wp-content/uploads/2019/11/CargaEconomica-Diabetes-en-Mexico-2013.pdf

32 Barquera S, Campos-Nonato I, Aguilar-Salinas C, et al. Diabetes in Mexico: cost and management of diabetes and its complications and challenges for health policy. Global Health 2013;9:3.

33 Global Burden of Disease Collaborative Network. Global burden of disease study 2016 (GBD 2016) disability weights. Institute for health metrics and evaluation (IHME), 2017. Available: http://ghdx. healthdata.org/record/ihme-data/gbd-2016-disability-weights [Accessed 20 Aug 2020].

34 Augustovski F, Colantonio LD, Galante J, et al. Measuring the Benefits of Healthcare: DALYs and QALYs - Does the Choice of Measure Matter? A Case Study of Two Preventive Interventions. Int J Health Policy Manag 2018;7:120-36.

35 The World Bank. GDP per capita - Mexico | Data. Available: https:// data.worldbank.org/indicator/NY.GDP.PCAP.CD?end=2019\& locations $=$ MX\&start=1983 [Accessed 21 Aug 2020]

36 Hatswell AJ, Bullement A, Briggs A, et al. Probabilistic sensitivity analysis in cost-effectiveness models: determining model convergence in cohort models. Pharmacoeconomics 2018;36:1421-6.

37 Salomon JA, Carvalho N, Gutiérrez-Delgado C, et al. Intervention strategies to reduce the burden of non-communicable diseases in Mexico: cost effectiveness analysis. BMJ 2012;344:e355.

38 Watson SI, Sahota H, Taylor CA, et al. Cost-effectiveness of health care service delivery interventions in low and middle income countries: a systematic review. Glob Health Res Policy 2018;3:17.

39 Molina RL, Palazuelos D. Navigating and circumventing a fragmented health system: the patient's pathway in the Sierra Madre region of Chiapas, Mexico. Med Anthropol Q 2014;28:23-43.
40 Secretaría de Salud. Emite La Secretaría de Salud emergencia epidemiológica POR diabetes mellitus $\mathrm{Y}$ obesidad. gob.mx. Available: http://www.gob.mx/salud/prensa/emite-la-secretaria-desalud-emergencia-epidemiologica-por-diabetes-mellitus-y-obesidad [Accessed 24 Aug 2020].

41 Barquera S, Schillinger D, Aguilar-Salinas CA, et al. Collaborative research and actions on both sides of the US-Mexico border to counteract type 2 diabetes in people of Mexican origin. Global Health 2018;14:84.

42 Hernández Ávila M, Rivera Dommarco J, Shamah Levy T. Encuesta Nacional de Salud Y Nutrición de Medio Camino 2016. Instituto Nacional de Salud Pública, 2016. Available: http://promocion.salud. gob.mx/dgps/descargas1/doctos_2016/ensanut_mc_2016-310oct. pdf [Accessed 24 Apr 2017].

43 Salinas JJ, Al Snih S, Markides K. The rural-urban divide: health services utilization among older Mexicans in Mexico: rural health among older Mexicans. J Rural Health 2010;26:333-41.

44 Grogger J, Arnold T, León AS, et al. Heterogeneity in the effect of public health insurance on catastrophic out-of-pocket health expenditures: the case of Mexico. Health Policy Plan 2015;30:593-9.

45 Moreno-Estrada A, Gignoux CR, Fernández-López JC, et al. Human genetics. The genetics of Mexico recapitulates native American substructure and affects biomedical traits. Science 2014;344:1280-5.

46 Morgan CL, Currie CJ, Stott NC, et al. The prevalence of multiple diabetes-related complications. Diabet Med 2000;17:146-51.

47 Husereau D, Drummond M, Petrou S, et al. Consolidated health economic evaluation reporting standards (CHEERS)-explanation and elaboration: a report of the ISPOR health economic evaluation publication guidelines good reporting practices task force. Value Health 2013;16:231-50. 


\section{APPENDIX}

\section{Supplemental Methods}

\section{Study selection}

- Transition probabilities: To estimate the probability of achieving diabetes control with Compañeros En Salud Programa de Enfermedades Crónicas (CESPEC) compared to usual care, we utilized probabilities from our previous study that compared the two care models using a difference-indifferences approach. ${ }^{1}$ For other transition probabilities, we sought high quality studies from Mexico that would provide the rate or probability of developing diabetes complications, stratified by whether diabetes was controlled or uncontrolled. This level of detail was available in a Mexican setting for mortality, ${ }^{2}$ but was not available for other diabetes complications. To estimate the probability of developing these other diabetes complications, we selected three landmark diabetes trials conducted in Western nations..$^{3-5}$ The three studies we selected also carry the three highest study weights in a Cochrane review. ${ }^{6}$ To assess the risk of developing a macrovascular diabetes complications after already having a microvascular complication, we identified a study based on the ADVANCE trial to derive transition probabilities. ${ }^{7}$

- Costs: The estimation of the cost of the CESPEC intervention and usual care are detailed in the main manuscript. The cost of diabetes complications were drawn from a report by Barraza-Lloréns et al. that is based in the Mexican health care setting. This is the only study we identified that estimates a per person or per event cost for diabetes complications in Mexico. Other estimates of diabetes costs in Mexico reported in the literature are population-level studies that only report aggregated total costs for the entire Mexican health care system. ${ }^{8}$

- Health states: To calculate quality-adjusted life years (QALYs) reported in Appendix Table 1, we used disability weights from the Global Burden of Disease study given their comprehensiveness and established use in global health settings. ${ }^{9}$ Full details of the derivation of QALYs is reported below in the "Primary outcome" section.

Transition probability calculation

For multiple model parameters, the original studies reported outcomes as rates (outcome events per unit time). For a given rate $(r)$ and time period $(t)$, a transition probability $(p)$ was calculated using the following equation: ${ }^{10}$

$$
p=1-e^{-r t}
$$

For transition probability model parameters derived from multiple data sources (nephropathy, neuropathy, retinopathy, stroke and myocardial infarction), we then calculated a weighted average transition probability using the meta-analysis weights reported in a Cochrane analysis. ${ }^{6}$

\section{Sensitivity analysis: uncertainty of model parameters}

To characterize uncertainty in the probabilistic sensitivity analysis, we used beta distributions for binary outcomes and gamma distributions for costs. Distributions were fit for probabilistic sensitivity analysis by using the method of moments approach. ${ }^{10}$ Using this approach, we used the point estimate mean and standard errors reported by the selected studies to calculate distribution parameters. In one data source (BarrazaLloréns et al.), no standard errors were reported for the cost point estimates. This report calculated per person costs utilizing multiple studies. Where possible, we reviewed the original, referenced studies to derive the standard errors. If not available, we used existing standard errors from other estimates in the report to calculate new standard errors that were proportional to the magnitude of the cost estimate.

\section{Primary outcome}

We selected QALYs as our primary outcome for the cost-effectiveness analysis, given our aim to measure the effectiveness of an intervention, as opposed to an assessment of disease burden (for which disability-adjusted life years may be preferred). ${ }^{11}$ However, there is a lack of published utility weights for multiple diabetes health 
states and from low- and middle-income countries that we needed for our decision analysis model. Most utility weights that exist for diabetes are derived in high-income countries.$^{12}$ Instead of using available utility-weights from high-income countries, we took the approach of utilizing disability weights under the assumption that $Q=1$ $D$, where $Q$ is the utility weight and $D$ is the disability weight. Though there are differences in how utility and disability weights are derived, this approach provided several advantages. First, it allowed us to calculate QALYs for the entire model using a uniform set of disability weights from the Global Burden of Disease study that were derived using the same methodology. ${ }^{9}$ Second, these disability weights were developed for use in global health settings and low- and middle-income countries. Our approach has been evaluated empirically, ${ }^{13}$ and has been utilized in other cost-effectiveness analyses. ${ }^{14}$ Furthermore, studies evaluating the use of both QALYs and DALYs to determine cost-effectiveness usually lead to similar interpretations and conclusions. ${ }^{15}$ 


\section{Appendix Figure 1: Simplified Schematic Decision Tree}

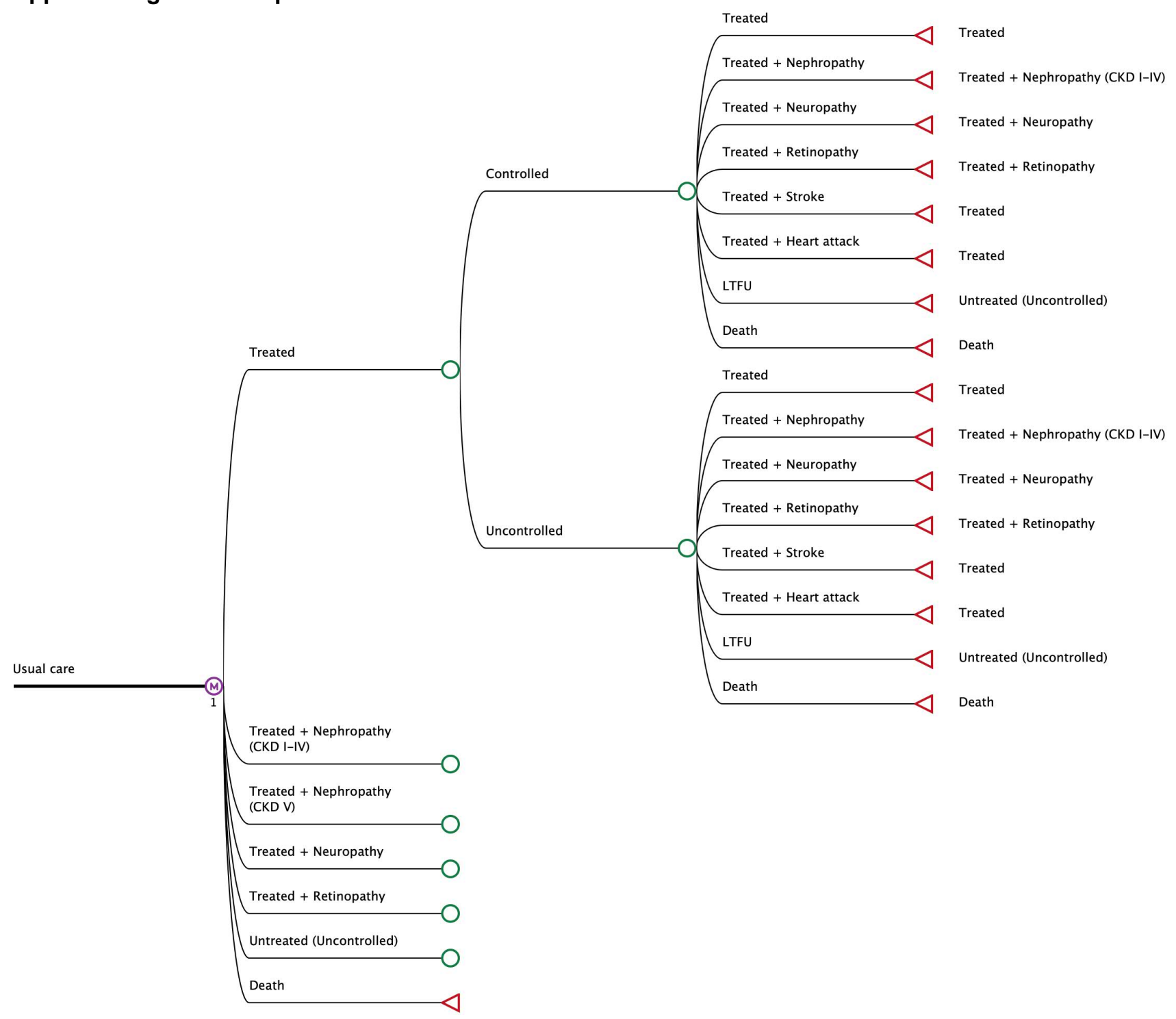


Appendix Table 1: Model Parameters for Cost-effectiveness Analysis

\begin{tabular}{|c|c|c|c|}
\hline Model Parameter & $\begin{array}{c}\text { Point } \\
\text { Estimate (SE) }\end{array}$ & Distribution & Source \\
\hline \multicolumn{4}{|l|}{$\begin{array}{l}\text { Costs of complications (2016 } \\
\text { US dollars) }\end{array}$} \\
\hline \multicolumn{4}{|l|}{ Per patient per year } \\
\hline Neuropathy & $\$ 69.02(6.11)$ & $\mathrm{Y}$ & Barraza-Lloréns et al $(2015)^{16}$ \\
\hline Retinopathy & $\begin{array}{l}\$ 369.08 \\
(32.69)\end{array}$ & $\mathrm{r}$ & Barraza-Lloréns et al $(2015)^{16}$ \\
\hline Nephropathy (CKD I-IV) & $\begin{array}{c}\$ 346.18 \\
(30.67)\end{array}$ & $\mathrm{Y}$ & Barraza-Lloréns et al $(2015)^{16}$ \\
\hline Nephropathy (CKD V) & $\begin{array}{c}\$ 19,445.84 \\
(1722.53)\end{array}$ & Y & Barraza-Lloréns et al $(2015)^{16}$ \\
\hline \multicolumn{4}{|l|}{ Per event } \\
\hline Stroke & $\begin{array}{l}\$ 13,328.20 \\
(912.65)\end{array}$ & Y & Barraza-Lloréns et al $(2015)^{16}$ \\
\hline Myocardial infarction & $\begin{array}{c}\$ 6,269.76 \\
(681.44)\end{array}$ & Y & Barraza-Lloréns et al (2015) ${ }^{16}$ \\
\hline \multicolumn{4}{|l|}{$\begin{array}{l}\text { Costs of programs ( } 2016 \text { US } \\
\text { dollars) }\end{array}$} \\
\hline \multicolumn{4}{|l|}{ Per patient per year } \\
\hline CESPEC & $\$ 143.69(2.29)$ & $\mathrm{Y}$ & Table 1 \\
\hline Usual care & $\$ 124.83(5.98)$ & $\mathrm{Y}$ & Table 1 \\
\hline \multicolumn{4}{|l|}{$\begin{array}{l}\text { Transition probabilities } \\
\text { (proportion of individuals per } \\
\text { year) }\end{array}$} \\
\hline \multicolumn{4}{|l|}{ Diabetes control $^{\mathrm{a}}$} \\
\hline Controlled in CESPEC & $0.526(0.018)$ & $B$ & Duan et al (2018) ${ }^{1}$ \\
\hline Controlled in usual care & $0.277(0.002)$ & $\beta$ & Duan et al $(2018)^{1}$ \\
\hline \multicolumn{4}{|l|}{ Neuropathy } \\
\hline Diabetes controlled & $0.081(0.028)^{b}$ & ß & $\begin{array}{l}\text { UKPDS (1998), }{ }^{3} \text { ACCORD (2008), }{ }^{4} \text { ADVANCE } \\
(2008)^{5}\end{array}$ \\
\hline Diabetes uncontrolled & $0.083(0.028)^{b}$ & ß & $\begin{array}{l}\text { UKPDS (1998), }{ }^{3} \text { ACCORD (2008), }{ }^{4} \text { ADVANCE } \\
(2008)^{5}\end{array}$ \\
\hline \multicolumn{4}{|l|}{ Retinopathy } \\
\hline Diabetes controlled & $0.014(0.002)^{b}$ & B & $\begin{array}{l}\text { UKPDS (1998), }{ }^{3} \text { ACCORD (2008), }{ }^{4} \text { ADVANCE } \\
(2008)^{5}\end{array}$ \\
\hline Diabetes uncontrolled & $0.015(0.002)^{b}$ & ß & $\begin{array}{l}\text { UKPDS (1998), }{ }^{3} \text { ACCORD (2008), }{ }^{4} \text { ADVANCE } \\
(2008)^{5}\end{array}$ \\
\hline \multicolumn{4}{|l|}{ Nephropathy (CKD I-IV) } \\
\hline Diabetes controlled & $0.055(0.036)^{b}$ & ß & $\begin{array}{l}\text { UKPDS (1998), }{ }^{3} \text { ACCORD (2008), }{ }^{4} \text { ADVANCE } \\
(2008)^{5}\end{array}$ \\
\hline Diabetes uncontrolled & $0.057(0.036)^{b}$ & B & $\begin{array}{l}\text { UKPDS (1998), }{ }^{3} \text { ACCORD (2008), }{ }^{4} \text { ADVANCE } \\
(2008)^{5}\end{array}$ \\
\hline \multicolumn{4}{|l|}{ Nephropathy (CKD V) } \\
\hline Diabetes controlled & $0.004(0.001)^{\mathrm{b}}$ & ß & $\begin{array}{l}\text { UKPDS (1998), }{ }^{3} \text { ACCORD (2008), }{ }^{4} \text { ADVANCE } \\
(2008)^{5}\end{array}$ \\
\hline Diabetes uncontrolled & $0.005(0.002)^{b}$ & ß & $\begin{array}{l}\text { UKPDS (1998), }{ }^{3} \text { ACCORD (2008), }{ }^{4} \text { ADVANCE } \\
(2008)^{5}\end{array}$ \\
\hline \multicolumn{4}{|l|}{ Stroke } \\
\hline Diabetes controlled & $0.006(0.001)^{b}$ & ß & $\begin{array}{l}\text { UKPDS (1998), }{ }^{3} \text { ACCORD (2008), }{ }^{4} \text { ADVANCE } \\
(2008)^{5}\end{array}$ \\
\hline Diabetes uncontrolled & $0.006(0.001)^{b}$ & B & $\begin{array}{l}\text { UKPDS (1998), }{ }^{3} \text { ACCORD (2008), }{ }^{4} \text { ADVANCE } \\
(2008)^{5}\end{array}$ \\
\hline $\begin{array}{l}\text { Existing microvascular } \\
\text { disease }\end{array}$ & $0.009(0.003)$ & ß & Mohammedi et al $(2017)^{7}$ \\
\hline \multicolumn{4}{|l|}{ Myocardial infarction } \\
\hline Diabetes controlled & $0.010(0.003)^{b}$ & ß & $\begin{array}{l}\text { UKPDS (1998), }{ }^{3} \text { ACCORD (2008), }{ }^{4} \text { ADVANCE } \\
(2008)^{5}\end{array}$ \\
\hline
\end{tabular}




\begin{tabular}{|c|c|c|c|}
\hline Diabetes uncontrolled & $0.013(0.004)^{b}$ & ß & $\begin{array}{l}\text { UKPDS (1998), }{ }^{3} \text { ACCORD (2008), }{ }^{4} \text { ADVANCE } \\
(2008)^{5}\end{array}$ \\
\hline $\begin{array}{l}\text { Existing microvascular } \\
\text { disease }\end{array}$ & $0.008(0.003)$ & ß & Mohammedi et al $(2017)^{7}$ \\
\hline \multicolumn{4}{|l|}{ All-cause death } \\
\hline Diabetes controlled & $0.010(0.001)$ & ß & Herrington et al (2018) ${ }^{2}$ \\
\hline Diabetes uncontrolled & $0.016(0.001)$ & $\beta$ & Herrington et al (2018) ${ }^{2}$ \\
\hline $\begin{array}{l}\text { Existing microvascular } \\
\text { disease }\end{array}$ & $0.026(0.006)$ & ß & Mohammedi et al $(2017)^{7}$ \\
\hline \multicolumn{4}{|l|}{ Quality of life (QALYs) } \\
\hline Diabetes (uncomplicated) & $0.951(0.010)$ & ß & IHME $(2017)^{9}$ \\
\hline Neuropathy & $0.867(0.025)$ & B & IHME $(2017)^{9}$ \\
\hline Retinopathy & $0.866(0.025)^{c}$ & $\beta$ & IHME $(2017)^{9}$ \\
\hline Nephropathy (CKD I-IV) & $0.922(0.015)^{c}$ & B & IHME $(2017)^{9}$ \\
\hline Nephropathy (CKD V) & $0.414(0.084)^{\mathrm{c}}$ & $ß$ & IHME $(2017)^{9}$ \\
\hline Stroke & $0.691(0.049)^{c}$ & $\beta$ & IHME $(2017)^{9}$ \\
\hline Myocardial infarction & $0.900(0.019)^{c}$ & $\beta$ & IHME $(2017)^{9}$ \\
\hline Discount rate & 0.03 & $\mathrm{~N} / \mathrm{A}$ & $\mathrm{N} / \mathrm{A}$ \\
\hline
\end{tabular}

$\mathrm{SE}=$ standard error; CKD=chronic kidney disease; CESPEC=Compañeros En Salud Programa de Enfermedades Crónicas; QALY=quality-adjusted life year; UKPDS=United Kingdom Prospective Diabetes Study; $A C C O R D=A c t i o n$ to Control Cardiovascular Risk in Diabetes; ADVANCE=Action in Diabetes and Vascular Disease; IHME=Institute of Health Metrics and Evaluation

${ }^{a}$ Diabetes control is defined by the Secretariat of Health of Chiapas as a hemoglobin A1c below $7 \%$ or (if not available) a fasting blood glucose level below $7.16 \mathrm{mmol} / \mathrm{l}(130 \mathrm{mg} / \mathrm{dl})$

${ }^{b}$ Weighted average based on meta-analysis weights in Hemmingsen et al $(2013)^{6}$

${ }^{c}$ Average of disability weights across disease state subcategories 


\section{Appendix Table 2: One-way Sensitivity Analysis results}

Model Parameter
Cost of CESPEC
Cost of usual care
Probability of diabetes control
in CESPEC
Probability of diabetes control
in usual care
Cost of nephropathy (CKD V)
Cost of stroke
Cost of nephropathy (CKD I-
IV)
Cost of myocardial infarction
Cost of neuropathy
Cost of retinopathy

\begin{tabular}{|c|c|c|c|c|c|}
\hline $\begin{array}{l}80 \% \text { Base } \\
\text { Case Value }\end{array}$ & $\begin{array}{c}\text { Base Case } \\
\text { Value }\end{array}$ & $\begin{array}{l}120 \% \text { Base } \\
\text { Case Value }\end{array}$ & ICER Low & ICER High & $\begin{array}{l}\text { ICER } \\
\text { Spread }\end{array}$ \\
\hline$\$ 114.95$ & $\$ 143.69$ & $\$ 172.43$ & Dominated & $\$ 6,407.25$ & $\$ 6,851.53$ \\
\hline$\$ 99.86$ & $\$ 124.83$ & $\$ 149.80$ & $\$ 253.11$ & $\$ 5,709.86$ & $\$ 5,456.75$ \\
\hline 0.42 & 0.53 & 0.63 & $\$ 2,096.32$ & $\$ 4,683.51$ & $\$ 2,587.19$ \\
\hline 0.22 & 0.28 & 0.33 & $\$ 2,550.64$ & $\$ 3,524.32$ & $\$ 973.68$ \\
\hline$\$ 15,556.67$ & $\$ 19,445.84$ & $\$ 23,335.01$ & $\$ 2,845.18$ & $\$ 3,117.80$ & $\$ 272.63$ \\
\hline$\$ 10,662.56$ & $\$ 13,328.20$ & $\$ 15,993.84$ & $\$ 2,953.02$ & $\$ 3,009.96$ & $\$ 56.93$ \\
\hline$\$ 276.94$ & $\$ 346.18$ & $\$ 415.42$ & $\$ 2,963.47$ & $\$ 2,999.51$ & $\$ 36.04$ \\
\hline$\$ 5,015.81$ & $\$ 6,269.76$ & $\$ 7,523.71$ & $\$ 2,968.56$ & $\$ 2,994.42$ & $\$ 25.86$ \\
\hline$\$ 55.22$ & $\$ 69.02$ & $\$ 82.82$ & $\$ 2,976.57$ & $\$ 2,986.40$ & $\$ 9.83$ \\
\hline$\$ 295.26$ & $\$ 369.08$ & $\$ 442.90$ & $\$ 2,978.24$ & $\$ 2,984.74$ & $\$ 6.50$ \\
\hline
\end{tabular}




\section{References}

1. Duan $\mathrm{K}, \mathrm{McBain} \mathrm{R}$, Flores $\mathrm{H}$, et al. Implementation and clinical effectiveness of a community-based noncommunicable disease treatment programme in rural Mexico: a difference-in-differences analysis. Health Policy Plan. Published online April 25, 2018. doi:10.1093/heapol/czy041

2. Herrington WG, Alegre-Díaz J, Wade R, et al. Effect of diabetes duration and glycaemic control on 14-year cause-specific mortality in Mexican adults: a blood-based prospective cohort study. The Lancet Diabetes \& Endocrinology. 2018;6(6):455-463. doi:10.1016/S2213-8587(18)30050-0

3. UK Prospective Diabetes Study (UKPDS) Group. Intensive blood-glucose control with sulphonylureas or insulin compared with conventional treatment and risk of complications in patients with type 2 diabetes (UKPDS 33). UK Prospective Diabetes Study (UKPDS) Group. Lancet. 1998;352(9131):837-853.

4. Ismail-Beigi F, Craven T, Banerji MA, et al. Effect of intensive treatment of hyperglycaemia on microvascular outcomes in type 2 diabetes: an analysis of the ACCORD randomised trial. The Lancet. 2010;376(9739):419-430. doi:10.1016/S0140-6736(10)60576-4

5. ADVANCE Collaborative Group, Patel A, MacMahon S, et al. Intensive blood glucose control and vascular outcomes in patients with type 2 diabetes. N Engl J Med. 2008;358(24):2560-2572. doi:10.1056/NEJMoa0802987

6. Hemmingsen B, Lund SS, Gluud C, Vaag A, Almdal TP, Wetterslev J. Targeting intensive glycaemic control versus targeting conventional glycaemic control for type 2 diabetes mellitus. In: The Cochrane Collaboration, ed. Cochrane Database of Systematic Reviews. John Wiley \& Sons, Ltd; 2013. doi:10.1002/14651858.CD008143.pub3

7. Mohammedi K, Woodward M, Marre M, et al. Comparative effects of microvascular and macrovascular disease on the risk of major outcomes in patients with type 2 diabetes. Cardiovasc Diabetol. 2017;16(1):95. doi:10.1186/s12933-017-0574-y

8. Barquera S, Campos-Nonato I, Aguilar-Salinas C, Lopez-Ridaura R, Arredondo A, Rivera-Dommarco J. Diabetes in Mexico: cost and management of diabetes and its complications and challenges for health policy. Global Health. 2013;9:3. doi:10.1186/1744-8603-9-3

9. Global Burden of Disease Collaborative Network. Global Burden of Disease Study 2016 (GBD 2016) Disability Weights. Institute for Health Metrics and Evaluation (IHME); 2017. Accessed August 20, 2020. http://ghdx.healthdata.org/record/ihme-data/gbd-2016-disability-weights

10. Briggs AH, Claxton K, Sculpher MJ. Decision Modelling for Health Economic Evaluation. Oxford University Press; 2006.

11. Gold MR, Stevenson D, Fryback DG. HALYs and QALYs and DALYs, Oh My: Similarities and Differences in Summary Measures of Population Health. Annu Rev Public Health. 2002;23(1):115-134. doi:10.1146/annurev.publhealth.23.100901.140513

12. Kennedy-Martin T, Paczkowski R, Rayner S. Utility values in diabetic kidney disease: a literature review. Current Medical Research and Opinion. 2015;31(7):1271-1282. doi:10.1185/03007995.2015.1041895

13. Augustovski F, Colantonio LD, Galante J, et al. Measuring the Benefits of Healthcare: DALYs and QALYs Does the Choice of Measure Matter? A Case Study of Two Preventive Interventions. Int J Health Policy Manag. 2018;7(2):120-136. doi:10.15171/ijhpm.2017.47

14. Heller DJ, Coxson PG, Penko J, et al. Evaluating the Impact and Cost-Effectiveness of Statin Use Guidelines for Primary Prevention of Coronary Heart Disease and Stroke. Circulation. 2017;136(12):10871098. doi:10.1161/CIRCULATIONAHA.117.027067 
15. Feng X, Kim DD, Cohen JT, Neumann PJ, Ollendorf DA. Using QALYs versus DALYs to measure costeffectiveness: How much does it matter? Int J Technol Assess Health Care. 2020;36(2):96-103. doi:10.1017/S0266462320000124

16. Barraza Lloréns M, Guajardo Barrón V, Picó J, et al. Carga Económica de La Diabetes Mellitus En México, 2013. Funsalud; 2015. https://funsalud.org.mx/wp-content/uploads/2019/11/Carga-Economica-Diabetesen-Mexico-2013.pdf 